\title{
Трансформация читательских практик в современном российском обществе
}

Аннотация: В статье рассматриваются проблемы читательской культуры современной России. Исследуется социально-демографические, экономические, технологические аспекты современных читательских практик. Важнейшим фактором изменения форм чтения в современном российском обществе является развитие информационных технологий и средств коммуникации, позволяющих хранить и передавать большие объемы информации. Это снижает актуальность традиционных практик чтения, на смену которым приходит справочно-поисковый тип работы с информацией, отвечающий образовательным стратегиям и стандартам информационной культуры «общества знаний». Анализ особенностей трансформации читательских практик в современном российском обществе основывается на обобщении результатов общероссийских социологических опросов, а такюе данных статистики. В статье показано, что в современном обществе существуют предпосылки для сохранения и развития традиционных институтов и форм читательской культуры. Такюе отмечается, что в контексте развития новых информационных технологий следует говорить не о кризисе чтения, а о трансформации чтения как социокультурной практики, обусловленной масштабами и темпами информатизации современного российского общества.

Review: The article is devoted to the problems of reading culture in modern Russia. The author of the article studies social and demographic, economic, technological aspects of modern reading practices. According to the author, the most important factor leading to the change in the form of reading is the development of information technologies and communication tools that allow to store and convey large volumes of information. This decreases the demand for traditional reading practices. Traditional reading is replaced with the search for information which complies with the modern educational strategies and standards of the information-based culture of the 'knowledge society'. The analysis of peculiarities of transformation of reading practices in modern Russian society is based on the generalization of the results of Russian surveys as well as statistics. However, the author of the article proves that the modern society has all necessary bases to keep and develop traditional institutions and forms of reading culture. The author also notes that in terms of the development of new information technologies, we should be talking not about the 'crisis' of reading but about transformation of reading as a socio-cultural practice conditioned by the scale and pace of electronic communication development of modern Russian society.

Ключевые слова: Социология чтения, социология культуры, социальная коммуникация, современная библиотека, читательская культура, информационное общество, общество знаний, е-образование, Интернет-коммуникация, информатизация общества.

Keywords: Sociology of reading, sociology of culture, social communication, modern library, reading culture, information-based society, knowledge society, e-education, Internet communication, electronic communication development of the society.

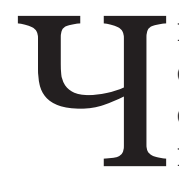
итательская культура - важнейшая составляющая современного общества. Чтение является неотъемлемой частью многообразных форм социальной деятельности, обеспечивающей воспроизводство культуры и общества. С конца XIX - начала XX веков благодаря распространению грамотности, развитию печатной периодики чтение постепенно приобрело массовый характер. В XXI веке в условиях формирования глобального информационного общества, «общества знаний» чтение, как и другие социальные практики, претерпевает определенные изменения. В России эти из- менения имеют свою социокультурную специфику, обусловленную характером политических и социально-экономических преобразований в постсоветский период. Негативные последствия этих преобразований, связанные с сокращением государственного финансирования многих сфер общества, отразились и на читательской культуре россиян.

С 1990 г. по 2012 г. в России на треть сократилось число общедоступных библиотек. В 1990 г. в России было 62,6 тыс. общедоступных библиотек, в 2000 г. - 51,2 тыс., в 2012 г. - 40,8 тыс. Не менее чем в два раза снизилось число общедоступных библиотек в городах и посел- 
ках городского типа с 20,4 тыс. до 9,7 тыс., на четверть в сельской местности - с 42,2 тыс. до 31,1 тыс. За указанный период в России сократился библиотечный фонд с 1155 млн. экз. до 864 млн. экз. Уменьшилось и число зарегистрированных пользователей. В 1990 г. их количество составляло 71,9 млн. чел., в 2000 г. 59,6 млн. чел., в 2012 г. - 52,2 млн. чел. ${ }^{~}$.

Несмотря на сокращение численности россиян, зарегистрированных в библиотеках, в 2012 г. их количество оставалось все же достаточно высоким. Это не менее трети населения России. Однако факт регистрации в библиотеке ничего не говорит о характере ее посещения. Как показывают результаты исследований социологов, активность пользователей библиотеками крайне низка. Согласно данным ФОМ (2013 г.), 30\% россиян никогда не были в библиотеке, а $52 \%$ были там более года назад. 70\% опрошенных считают, что сегодня россияне ходят в библиотеку значительно реже, чем 10-12 лет назад².

Снижение активности посетителей библиотек в постсоветский период связано, прежде всего, с коммерциализацией культуры и развитием книжного рынка в конце 80-х - начале 90-х годов XX века. Рынок открыл возможность свободной продажи тех книг, которые в советские времена могли входить в группу дефицитных товаров. Развитие книжного рынка позволило приобретать книги в личную собственность, что для некоторых групп читателей могло быть более привлекательным, чем посещение библиотеки. В 90-е годы, когда остро встал вопрос о выживании практически всех сфер общества, а также многих социальных групп, снизилась социальная значимость и ценность чтения и соответственно таких институтов хранения и распространения книжной культуры, как библиотека.

Редукция функций библиотек к хранению информации, утрата библиотеками социокультурного влияния, свойственного индустриальному обществу, - это тенденция, характерная не только для России. По мнению $\Phi$. Уэбстера, в современном информационном обществе коммерциализация (превращение информации в товар) подрывает базовые принципы функционирования библиотек свободный доступ к информации и универсальное обслуживание ${ }^{3}$.

\footnotetext{
${ }^{1}$ Российский статистический ежегодник. 2013: Стат. сб. / Росстат. М., 2013. С. 254.

${ }^{2}$ О библиотеках: «превратить в культурные центры» // URL: fom.ru/Kultura-i-dosug/10797.

3 Уэбстер Ф. Теории информационного общества. М.: Аспект Пресс, 2004. (400 с.) С. 246-247.
}

На фоне уменьшения количества общедоступных библиотек, в России увеличилось число изданных книг и брошюр. В 1990 г. их количество составляло 41 тыс., в 2000 г. 60 тыс., а в 2012 г. - 123 тыс. Однако, тираж изданных книг и брошюр сокращался. С 1990 г. по 2012 г. общий тираж сократился почти в три раза с 1553 млн. экз. до 613 млн. экз. ${ }^{4}$. Подобная картина складывается и в сфере издания периодической печати. По сравнению с 1990 г. в современной России заметно выросло число издаваемых журналов и газет. Если в 1990 г. их число составляло 3681 и 4808 соответственно, то в 2012 г. - 8051 и 10681. При этом годовой тираж журналов сократился примерно в два с половиной раза (с 5010 млн. экз. до 1838 млн. экз.). А вот тираж газет увеличился с 166 млн. экз. до 238 млн. экз. 5 Эти данные можно рассматривать как показатель сужения объема читательского внимания, дифференциации читательских предпочтений и роста интереса к актуальной оперативной информации, позволяющей ориентироваться в текущих событиях.

Коммерциализация культуры как один из первостепенных факторов, определяющих ситуацию с книжной культурой и чтением в современной России, сказывается на понижении культурных запросов. Происходит смещение центра и периферии семиосферы российского общества, а вместе с таким смещением и изменение ценностно-нормативных приоритетов и культурных стандартов. Если массовая культура становится центром культурной подсистемы общества, то ее сущностные черты начинают определять правила производства книжной продукции и читательских практик. В условиях коммерциализации и массовизации культуры чтение становится одной из форм досуга и таком качестве может рассматриваться читателями как времяпрепровождение, способ «убить время». Развлекательный характер чтения ориентируют читателя на восприятие упрощенных моделей реальности, которым соответствуют упрощенные способы ее эстетизации и репрезентации. Это позволяет объяснить тот факт, что на фоне роста числа издаваемой книжной и периодической печатной продукции, социологические исследования фиксируют уменьшения числа читающих россиян, а также поверхностный характер читательских предпочтений, ориен-

4 Российский статистический ежегодник. 2013: Стат. сб. / Росстат. М., 2013. С. 255.

${ }_{5}$ Там же. С. 255. 
тацию читателей на развлекательные жанры. Согласно исследованиям «Левада-Центра», с 1990 г. по 2011 г. увеличилось число не читающих жителей России. Если в 1990 г. практически никогда не читали книг 19\%, то в 2011 г. уже 45\%. Также за указанный период возросло количество тех, кто не читает газеты с 5\% до $27 \%$, а тех, кто не читает журналы с $10 \%$ до 46\% ${ }^{6}$. Как показывают данные ВЦИОМ, в 2014 г. у читающей публики лидирующие позиции занимают романы о любви, «женские романы» (13\%), за ними следуют книги по истории, исторические романы (11\%). Остальные жанры (зарубежные детективы, «русский женский детектив», классическая русская и зарубежная литература, фантастика и т.д.) были названы менее чем 10\% респондентов7.

Чтение - это интеллектуальный процесс, который предполагает усиление внимания, работу воображения, активизацию мышления. Поэтому в условиях доминирования современных форм экранной культуры чтение уступает визуальной коммуникации, которая в силу «аналогической природы» допускает упрощенные формы перцепции (без декодирования $)^{8}$, особенно когда это касается произведений (реклама, массовое кино), не требующих специальной подготовки. Отмеченная специфика чтения предопределяет необходимость временных затрат. Традиционные практики чтения не позволяют экономить время так, как это можно сделать с помощью визуальных средств коммуникации или их комбинирования с вербальными средствами (креолизованный текст). Примером является инфографика, позволяющая доходчиво изложить ключевые положения сложных для восприятия текстов посредством «свертывания» тематических и смысловых блоков.

В связи с этим можно говорить о том, что фактором, ограничивающим частоту чтения и влияющим на читательские предпочтения, является экономическая ситуация и потребительские стандарты, побуждающие россиян тратить время на зарабатывание средств и поиски дополнительных источников дохода. Например, по данным социологического исследования, проведенного в 2008 г. в г. Бар-

\footnotetext{
${ }^{6}$ Общественное мнение - 2011. М.: Левада-Центр, 2012. C. 254. URL: http://www.levada.ru/books/obshchestvennoe-mnenie-2011

7 «Что читаем?» Пресс-выпуск №2596. 02.06.2014 // URL: http://wciom.ru/index.php?id=459\&uid=114843

${ }^{8}$ Барт Р. Избранные работы: Семиотика. Поэтика. М.: Издательская группа «Прогресс», «Универс», 1994. С. 309.
}

наул, вторичная занятость была характерна для $83,6 \%$ работников образования 9 . Исследования в Ульяновской области показали, что 14,7\% жителей сельской местности имеют вторичную занятость, а 54,0\% выражают желание найти дополнительную работу ${ }^{10}$. Как отмечают исследователи, вторичная занятость негативно сказывается на физическом и моральном состоянии работника, уровне его профессионализма ${ }^{11}$ и, как следствие, не способствует развитию читательской культуры. В этой связи целесообразно обратить внимание на следующий факт. Как показывают результаты социологических опросов ФОМ, в январе 2014 г. 24\% россиян заявили, что не читают, потому что у них нет для этого времени ${ }^{12}$.

В условиях напряженного рабочего графика, поглощения времени трудовой деятельностью слушание «на ходу» или смотрение «одним глазом» становятся более привлекательными, а порой и оптимальными, формами получения информации. Мобильные устройства в сочетании с Интернетом, повышают значимость информационных технологий и средств коммуникации. На передний план выходят многообразные способы манипулирования информацией (поиск, обработка, систематизация, фильтрация и т.д.), которую можно получить с помощью разнотипных устройств (смартфоны, планшеты, разные браузеры и почтовые серверы и т.д.). Плюрализм способов передачи и хранения информации становится важнейшим условием работы с ней.

Развитие новых информационных технологий и средств коммуникации является одной из причин утраты современными библиотеками их прежней социокультурной роли. По меткому замечанию Б. Дубина, российская массовая библиотека 90-х - начала 2000-х годов - это «справочное бюро». Помимо образовательных запросов школьников, студентов и ученых,

\footnotetext{
9 Зайцева T.М. Вторичная занятость работников образования крупного города (на материалах Барнаула) // Известия Алтайского государственного университета. 2010. №1-2. С. 336.

${ }^{10}$ Постнова М.В., Егорова М.А. Анализ масштабов вторичной занятости на сельском рынке труда Ульяновской области // Известия Оренбургского государственного аграрного университета. 2008. Т.2. №18-1. C. 146.

${ }^{11}$ Дукарт C.A., Слета Е.В. Проблемы оценки трансформации рынка труда в условиях модернизации экономики // Известия Томского политехнического университета. 2010. Т. 316. № 6. С. 11.

${ }_{12}$ Опрос: 56\% жителей России не читают художественную литературу // URL: http://pro-books.ru/
} news/3/14545 
она была ориентирована на некоторую часть взрослого населения, не имеющую собственных печатных ресурсов или использующую библиотеку как резервное хранилище ${ }^{13}$. Сегодня эту функцию берет на себя Интернет, под интенсивным воздействием которого оказались читательские практики россиян с конца 90-х годов. Рост числа интернет-пользователей не мог не отразиться на снижении популярности библиотек и традиционных форм чтения. Сoгласно данным ФОМ, весной 2003 г. суточная доля ежедневно выходящих в сеть Интернет россиян составляла $36 \%$ от всех пользователей сети, а весной 2014 г. уже $82 \%{ }^{14}$.

Одна из особенностей современной инфосферы - это высокая скорость передачи больших объемов информации. Современный человек погружен в высокоскоростной режим профессиональной, досуговой и семейной жизни. В условиях высокой занятости и отсутствия свободного времени для чтения, как и в ситуации противоположной - наличия свободного времени, которое тратится на развлечение, формируется новый, поисковосправочный тип чтения. Быстрота доступа к многообразной информации посредством электронных носителей способна породить у пользователей сомнение в необходимости усвоения знаний, к которым всегда имеется оперативный доступ в режиме «вездесущности». Интернет и мобильные электронные устройства позволяют обращаться к чтению при необходимости, «по требованию». Чтение при этом уподобляется «путешествию» по базам данных, организованным как гипертекст. Это деактуализирует потребности в печатной продукции и вытесняет бумажную книгу и журнал из области читательских практик и с книжного рынка. Так, согласно опросу ФОМ, в 2012 г. $19 \%$ россиян выбирали электронный формат чтения (ПК, ноутбук, планшет, смартфон) $)^{15}$.

Наиболее активными пользователями Интернета является молодежь, поэтому модификация форм чтения и читательских предпочтений касается прежде всего данной социальной группы. Однако нельзя утверждать, что именно молодежи, восприимчивой к инновациям и легко осваивающей новые формы коммуника-

\footnotetext{
${ }_{13}$ Дубин Б. Классика, после и рядом. Социологические очерки о литературе и культуре. М.: НЛО, 2010. С. $179-180$.

${ }^{14}$ Интернет в России: динамика проникновения. Весна 2014 г. // URL: http://runet.fom.ru/Proniknovenieinterneta/11567

${ }^{15} 19 \%$ россиян предпочитают чтение в электронном формате // URL: http://pro-books.ru/news/3/1289o.
}

ции, в наибольшей степени свойственна эрозия традиционных форм чтения, порожденная развитием информационных технологий. Например, на характере чтения студенческой молодежи сказывается специфика ее образа жизни и социализации. Вовлеченные в образовательный процесс представители молодежи чаще других оказываются в ситуации необходимости обращаться к «серьезному» чтению. Как показывают результаты опросов ВЦИOM (2014 г.), каждый десятый представитель молодежи в возрасте 18-24 лет обращался не только к развлекательной литературе, но также к научной, профессиональной и общественно-политической ${ }^{16}$. Поэтому оптимистические тенденции на современном книжном рынке исследователи видят в положительной динамике продаж детской и учебной литературы ${ }^{17}$.

Современное образование не является изолированным от происходящих в обществе процессов, в том числе от коммерциализации. Сегодня система образования уменьшает долю общекультурной информации и делает упор на специальные знания, хотя, пожалуй, именно образование является одним из институтов, обеспечивающих не только политическое и экономическое, но и культурное воспроизводство общества. Коммерциализация образования сказывается на изменении отношения к чтению. Если знание сегодня - это сумма сведений, обладающая оперативно-справочной ценностью (не попасть в автомобильную пробку, найти нужный адрес или номер телефона, не утруждая себя сдать экзамен и т.п.), то фундаментальные знания сохраняют свою ценность, в первую очередь, для узкой группы профессионалов. Сведения, которые оказываются бесполезны, неэффективны или не отвечают конъюнктуре рынка, становятся невостребованными. Ценными признаются те знания, которые обладают утилитарной направленностью и обеспечивают социально-экономическую успешность ${ }^{18}$. Коммерциализация образования и превращение знаний в товар приводит к тому, что образовательные структуры сегодня существуют

\footnotetext{
16 «Что читаем?» Пресс-выпуск №2596. 02.06.2014 // http://wciom.ru/index.php?id=459\&uid=114843.

${ }^{17}$ Книжный рынок: столичные тенденции // Университетская книга. 2013. № 10. C. 26-30. URL: http:// www.unkniga.ru/bookrinok/knigniy-rinok/2444knizhniy-rynok-stolichnye-tenedentsii.html

${ }^{18}$ Багдасарьян Н.Г. Ценность образования в модернизирующемся обществе, или Ценность знания в обществе незнания // Педагогика. 2008. №5. С. 8; Уэбстер Ф. Указ. соч. С. 345-348.
} 
уже не столько в культурном пространстве, сколько на рынке образовательных услуг. Они должны обладать высокопрофессиональным менеджментом, предлагать потребителю качественный продукт, эффективно использовать маркетинговые инструменты для продвижения своих услуг на рынке.

Современная государственная политика в сфере образования, ориентированная на поиски путей оптимизации деятельности вузов и решение проблемы последующего трудоустройства выпускников, также развивается в рамках экономикоцентричной парадигмы. Как отмечают эксперты, несмотря на позитивные тенденции государственной политики в области модернизации образования, такая политика не учитывает тот факт, что современные вузы являются не только центрами образования и науки, но и центрами культуры ${ }^{19}$. Поэтому развитие активных форм чтения определяется в том числе культурологической нагрузкой вуза.

В то же время использование в образовательном процессе современных информационнокоммуникационных технологий, подрывающих основы традиционных читательских практик, можно рассматривать как альтернативу экономическим ограничениям чтения в условиях рыночных отношений. Одним из факторов, снижающих потребительскую активность на рынке печатной продукции, является рост стоимости бумажных книг. Аналитики книжного рынка подчеркивают, что в деле книгоиздания и книготорговли цена играет ключевую роль как для потребителя, так и для определения бизнес-стратегии компании на рынке. Сегодняшняя ситуация характеризуется ростом цен на книжную продукцию. Это ведет к снижению покупательской активности и негативно сказывается на профессиональной деятельности издателей и представителей ритейла ${ }^{20}$. Использование электронных версий печатных изданий и снимает проблему финансовых затрат на приобретение книг и тем самым повышает привлекательность чтения с помощью электронных носителей.

Ориентация современного общества на внедрение стандартов «общества знаний» в информационной сфере является одной из наиболее существенных причин трансформации читательских практик. Применительно

\footnotetext{
19 От модернизации высшего образования к модернизации российского общества / Под ред. Г.К. Овчинникова. М.: МГИУ, 2008. С. 96-97.

${ }^{20}$ Книжный рынок: столичные тенденции // Университетская книга. 2013. № 10. C. 26-30. URL: http:// www.unkniga.ru/bookrinok/knigniy-rinok/2444knizhniy-rynok-stolichnye-tenedentsii.html
}

к образованию эти стандарты предполагают непрерывность обучения и образования в течение всей жизни и формирование инновационной личности, многофункциональность процесса обучения, ориентированность на развитие множественности форм разума, сетевой принцип обучения. Применение электронных средств обучения (e-learning) выдвигает новые требования к образовательному процессу. Это быстрота и неограниченность доступа ко всем необходимым информационным материалам, незавершенность и эпизодичность научных исследований, превращение производящих знания структур в виртуальные сообщества, замена трансляции знаний навигацией по информационным системам ${ }^{21}$. В логику формирования такой информационной культуры укладывается и появление новых форм чтения, обусловленных развитием и распространением сети Интернет, мобильных компьютеров, гаджетов. При этом следует отметить, что сегодня отсутствуют основания считать, что традиционные институты и формы читательской культуры безвозвратно уходят в прошлое.

Исчезновение библиотек означало бы исчезновение бумажной книги. Однако, тот факт, что бумажная книга остается популярной среди некоторой части населения, позволяет говорить о наличии у нее конкурентных преимуществ по сравнению с ее электронными версиями. В определенных условиях бумажная книга по сравнению с электронной оказывается функциональней и эргономичней. Нельзя исключать и психологического удовольствия, которое способен испытывать читатель, держащий в руках бумажную книгу: «Читать с дисплея - это совсем не то же самое, что читать со страницы» (У. Эко).

Развитие современной книги идет по пути совмещения бумажного и электронного форматов. Книгоиздатели практикуют выпуск бумажных книг, снабженных дисками,

${ }^{21}$ Бехманн $Г$. Современное общество: общество риска, информационное общество, общество знаний. М: Логос, 2010. С. 136-137; Гендина Н.И. Образование для общества знаний и проблемы формирования информационной культуры личности // Научные и технические библиотеки. 2007. № 3. С. 7; К обществам знания. Всемирный доклад ЮНЕСКО // URL: http:// unesdoc.unesco.org/images/oo14/oo1418/141843r.pdf; Труфанова Е.О., Яновская О.Р. Институт образования в обществе знаний // Педагогика и просвещение. 2012. №3. С. 30-43; Щупленков О.В., Щупленков Н.О. Проблема формирования инновационной личности в современном обществе // NB: Психология и психотехника. 2013. №8. C. 21-70. URL: http://www.enotabene.ru/psp/article_10493.html. 
содержащими электронную версию книги. Разработчики электронной книги стремятся приблизить качество изображения текста на экране к бумажному варианту, чтобы у читателя не возникало ощущение перцептивного дискомфорта. По-видимому, использование той или иной разновидности издания будет определяться его функциональной нагрузкой, местом, временем и целями использования.

Перспективы сохранения и развития библиотек определяются изменением их места и роли в информационной сфере. На это существует запрос у российского общества. Согласно социологическим данным ФОМ (2014 г.), 59\% россиян уверены в том, что будущее библиотек в современной России связано с их преобразованием в культурные центры ${ }^{22}$. Осознание необходимости реформирования библиотечной системы свойственно и профессиональному сообществу. Его представители видят выход в модернизации библиотек, в использовании маркетинговых средств для укрепления позиций библиотек на рынке информационных услуг. В числе приоритетных направлений модернизации библиотеки эксперты, ученые, маркетологи видят такие изменения, которые в новых условиях сделают библиотеки ближе к потенциальным посетителям. Речь идет об изменении системы оплаты и стимулирования труда, расширении набора функций и спектра услуг, технологических и содержательных реформах в сфере информатизации, ориентации на определенные группы населения ${ }^{23}$.

Библиотека - это институционально организованная форма деятельности, имеющая не только свои культурные традиции, но и стан- дарты работы по систематизации, хранению и поиску информации, являющиеся частью современной читательской культуры. Сегодня, как говорилось выше, часть этих функций переходят к новым информационно-коммуникационным технологиям. Однако, наличие программного обеспечения, которое вытесняет профессию библиотекаря как помощника читателя, не может заменить профессионала, особенно когда сам пользователь программы, читатель, систематизируя файлы книг в своем электронном устройстве, впоследствии затрудняется найти необходимый продукт. Также нельзя не согласиться с исследователями, считающими, что вовлеченность молодежи в читательские практики зависит от семьи (образования, культуры родителей), специальности и престижности вуза. Эти факторы обеспечивают успешное совмещение традиционных форм чтения с активным освоением современных информационных технологий и средств коммуникации, предопределяющих появление новых моделей поведения читателя ${ }^{24}$.

Таким образом, характеристики чтения как социокультурной практики в современной России в терминах «кризиса» или «эрозии» представляются недостаточно правомерными. В контексте парадигмы «общества знаний» следует говорить о трансформации чтения, обусловленной масштабами и темпами информатизации современного российского общества. Сегодня наблюдается модификация практик чтения, появление новых форм чтения в условиях технологических инноваций в сфере коммуникации, изменение читательских предпочтений и моделей работы с информацией.

\section{Библиография:}

1. Багдасарьян Н.Г. Ценность образования в модернизирующемся обществе, или Ценность знания в обществе незнания // Педагогика. 2008. №5.

2. Барт Р. Избранные работы: Семиотика. Поэтика. М.: Издательская группа «Прогресс», «Универс», 1994.

3. Бехманн Г. Современное общество: общество риска, информационное общество, общество знаний. М: Логос, 2010.

4. Гендина Н.И. Образование для общества знаний и проблемы формирования информационной культуры личности // Научные и технические библиотеки. 2007. № 3.

5. Дубин Б. Классика, после и рядом. Социологические очерки о литературе и культуре. М.: НЛО, 2010.

6. Дукарт С.А., Слета Е.В. Проблемы оценки трансформации рынка труда в условиях модернизации экономики // Известия Томского политехнического университета. 2010. Т. 316. № 6.

${ }^{22}$ О библиотеках: «превратить в культурные центры» // URL: fom.ru/Kultura-i-dosug/10797

${ }_{23}$ Московские библиотеки: концепция брендинга // URL: http://www.unkniga.ru/biblioteki/bibdelo/3318moskovskie-biblioteki-koncepciya-brendinga.html

\footnotetext{
${ }^{24}$ Юмашева Н.Д. Чтение как практика культурного воспроизводства в студенческой среде. Автореф. дисс... канд. социол. наук. М., 2008. С. 7.
} 
7. Зайцева Т.М. Вторичная занятость работников образования крупного города (на материалах Барнаула) // Известия Алтайского государственного университета. 2010. №1-2.

8. Интернет в России: динамика проникновения. Весна 2014 г. // URL: http://runet.fom.ru/Proniknovenieinterneta/11567

9. К обществам знания. Всемирный доклад ЮНЕСКО // URL: http://unesdoc.unesco.org/ images/0014/001418/141843r.pdf

10. Книжный рынок: столичные тенденции // Университетская книга. 2013. № 10. С. 26-30.

11. Московские библиотеки: концепция брендинга // URL: http://www.unkniga.ru/biblioteki/bibdelo/3318moskovskie-biblioteki-koncepciya-brendinga.html

12. О библиотеках: «превратить в культурные центры» // URL: fom.ru/Kultura-i-dosug/10797.

13. Общественное мнение - 2011. М.: Левада-Центр, 2012. С. 254. URL: http://www.levada.ru/books/ obshchestvennoe-mnenie-2011

14. Опрос: 56\% жителей России не читают художественную литературу // URL: http:/pro-books.ru/ news $/ 3 / 14545$

15. От модернизации высшего образования к модернизации российского общества / Под ред. Г.К. Овчинникова. М.: МГИУ, 2008.

16. Постнова М.В., Егорова М.А. Анализ масштабов вторичной занятости на сельском рынке труда Ульяновской области // Известия Оренбургского государственного аграрного университета. 2008. Т.2. №18-1.

17. Труфанова Е.О., Яновская О.Р. Институт образования в обществе знаний // Педагогика и просвещение. 2012. №3. С. 30-43.

18. Российский статистический ежегодник. 2013: Стат. сб. / Росстат. - М., 2013.

19. Уэбстер Ф. Теории информационного общества. М.: Аспект Пресс, 2004. (400с.) С. 246-247.

20. «Что читаем?» Пресс-выпуск №2596. 02.06.2014 // URL: http://wciom.ru/index.php?id=459\&uid=114843

21. Щупленков О.В., Щупленков Н.О. Проблема формирования инновационной личности в современном обществе // NB: Психология и психотехника. 2013. №8. С. 21-70. URL: http://www.e-notabene.ru/psp/ article_10493.html

22. Юмашева Н.Д. Чтение как практика культурного воспроизводства в студенческой среде. Автореф. дисс... канд. социол. наук. М., 2008.

23. $19 \%$ россиян предпочитают чтение в электронном формате // URL: http://pro-books.ru/news/3/12890.

\section{References (transliterated):}

1. Bagdasar'yan N.G. Tsennost' obrazovaniya v moderniziruyushchemsya obshchestve, ili Tsennost' znaniya v obshchestve neznaniya // Pedagogika. 2008. №5.

2. Bart R. Izbrannye raboty: Semiotika. Poetika. M.: Izdatel'skaya gruppa «Progress», «Univers», 1994.

3. Bekhmann G. Sovremennoe obshchestvo: obshchestvo riska, informatsionnoe obshchestvo, obshchestvo znanii. M: Logos, 2010.

4. Gendina N.I. Obrazovanie dlya obshchestva znanii i problemy formirovaniya informatsionnoi kul'tury lichnosti // Nauchnye i tekhnicheskie biblioteki. 2007. № 3.

5. Dubin B. Klassika, posle i ryadom. Sotsiologicheskie ocherki o literature i kul'ture. M.: NLO, 2010.

6. Dukart S.A., Sleta E.V. Problemy otsenki transformatsii rynka truda v usloviyakh modernizatsii ekonomiki // Izvestiya Tomskogo politekhnicheskogo universiteta. 2010. T. 316. № 6.

7. Zaitseva T.M. Vtorichnaya zanyatost' rabotnikov obrazovaniya krupnogo goroda (na materialakh Barnaula) // Izvestiya Altaiskogo gosudarstvennogo universiteta. 2010. №1-2.

8. Internet v Rossii: dinamika proniknoveniya. Vesna 2014 g. // URL: http://runet.fom.ru/Proniknovenie-interneta/ 11567

9. $\mathrm{K}$ obshchestvam znaniya. Vsemirnyi doklad YuNESKO // URL: http://unesdoc.unesco.org/ images/0014/001418/141843r.pdf

10. Knizhnyi rynok: stolichnye tendentsii // Universitetskaya kniga. 2013. № 10. S. 26-30.

11. Moskovskie biblioteki: kontseptsiya brendinga // URL: http://www.unkniga.ru/biblioteki/bibdelo/3318-moskovskie-biblioteki-koncepciya-brendinga.html

12. O bibliotekakh: «prevratit' v kul'turnye tsentry» // URL: fom.ru/Kultura-i-dosug/10797.

13. Obshchestvennoe mnenie - 2011. M.: Levada-Tsentr, 2012. S. 254. URL: http://www.levada.ru/books/obshchestvennoe-mnenie-2011 
14. Opros: $56 \%$ zhitelei Rossii ne chitayut khudozhestvennuyu literaturu // URL: http://pro-books.ru/news/3/14545

15. Ot modernizatsii vysshego obrazovaniya k modernizatsii rossiiskogo obshchestva / Pod red. G.K. Ovchinnikova. M.: MGIU, 2008.

16. Postnova M.V., Egorova M.A. Analiz masshtabov vtorichnoi zanyatosti na sel'skom rynke truda Ul'yanovskoi oblasti // Izvestiya Orenburgskogo gosudarstvennogo agrarnogo universiteta. 2008. T.2. №18-1.

17. Trufanova E.O., Yanovskaya O.R. Institut obrazovaniya v obshchestve znanii // Pedagogika i prosveshchenie. 2012. №3. C. 30-43.

18. Rossiiskii statisticheskii ezhegodnik. 2013: Stat. sb. / Rosstat. - M., 2013.

19. Uebster F. Teorii informatsionnogo obshchestva. M.: Aspekt Press, 2004. (400 s.) S. 246-247.

20. «Chto chitaem?» Press-vypusk №2596. 02.06.2014 // URL: http://wciom.ru/index.php?id=459\&uid=114843

21. Shchuplenkov O.V., Shchuplenkov N.O. Problema formirovaniya innovatsionnoi lichnosti v sovremennom obshchestve // NB: Psikhologiya i psikhotekhnika. 2013. №8. C. 21-70. URL: http://www.e-notabene.ru/psp/article 10493.html

22. Yumasheva N.D. Chtenie kak praktika kul'turnogo vosproizvodstva v studencheskoi srede. Avtoref. diss... kand. sotsiol. nauk. M., 2008.

23. $19 \%$ rossiyan predpochitayut chtenie v elektronnom formate // URL: http://pro-books.ru/news/3/12890. 